\title{
Estratégias de conscientização via rádio: um projeto de extensão contra a COVID-19
}

\section{Radio Awareness campaign Strategies: An Extension Project Against COVID-19}

DOI: $10.46919 / \operatorname{archv2n3-027}$

Recebimento dos originais: 01/01/2021

Aceitação para publicação: 31/03/2021

\section{Leandro Luiz da Silva}

Acadêmico de fisioterapia, pela Universidade Estadual do Norte do Paraná - UENP

Centro de Ciências da Saúde - CCS

Endereço: Alameda Padre Magno, 841, Nova Jacarezinho- Jacarezinho, Paraná, CEP: 86400-000

E-mail: silva.leandrol@hotmail.com

\section{Rafaela Maria de Souza}

Fisioterapeuta, pela Universidade Estadual do Norte do Paraná - UENP

Centro de Ciências da Saúde - CCS

Endereço: Alameda Padre Magno, 841, Nova Jacarezinho- Jacarezinho, Paraná, CEP: 86400-000

E-mail: desouzarafaelamaria@gmail.com

\section{Nicoly Teixeira dos Santos}

Acadêmica de fisioterapia, pela Universidade Estadual do Norte do Paraná - UENP Centro de Ciências da Saúde - CCS

Endereço: Alameda Padre Magno, 841, Nova Jacarezinho - Jacarezinho, Paraná, CEP: 86400-000

E-mail: nicolyts@ hotmail.com

\section{Karina Arielle da Silva Souza}

Especialista em Fisioterapia Aplicada à Pneumologia, pela Universidade Estadual Paulista "Júlio de Mesquita Filho"- UNESP

Instituição: Universidade Estadual do Norte do Paraná - UENP

Endereço: Alameda Padre Magno, 841, Nova Jacarezinho - Jacarezinho, Paraná, CEP: 86400-000

E-mail: karina.souza@uenp.edu.br

\section{Paolla de Oliveira Sanches}

Especialista em Fisioterapia Aplicada à Pneumologia, pela Universidade Estadual Paulista "Júlio de Mesquita Filho"- UNESP

Instituição: Universidade Estadual do Norte do Paraná - UENP

Endereço: Alameda Padre Magno, 841, Nova Jacarezinho - Jacarezinho, Paraná, CEP: 86400-000 E-mail: paolla.sanches@uenp.edu.br

\section{Fábio Antonio Néia Martini}

Doutor em ciências do desporto, pela Universidade Trás os Montes e Auto Douro - Vila Real - Portugal Instituição: Universidade Estadual do Norte do Paraná - UENP

Endereço: Alameda Padre Magno, 841, Nova Jacarezinho - Jacarezinho, Paraná, CEP: 86400-000 E-mail: famartini@uenp.edu.br

Fabrício José Jassi

Doutor em Reabilitação e Desempenho Funcional, pela Universidade de São Paulo-USP Instituição: Universidade Estadual do Norte do Paraná - UENP 
Endereço: Alameda Padre Magno, 841, Nova Jacarezinho - Jacarezinho, Paraná, CEP: 86400-000 E-mail: fjjassi@uenp.edu.br

Mahara Daian Garcia Lemes Proença

Doutora em Ciências da Saúde, pela Universidade Estadual de Londrina- UEL

Instituição: Universidade Estadual do Norte do Paraná - UENP

Endereço: Alameda Padre Magno, 841, Nova Jacarezinho - Jacarezinho, Paraná, CEP: 86400-000

E-mail: mahara.proenca@uenp.edu.br

\title{
RESUMO
}

A doença do coronavírus 2019 (COVID-19) se trata de uma doença respiratória infecciosa de causa viral, tendo sua origem naChina e logo se espalhou por todo o mundo se tornando uma pandemia e emergência de saúde pública. A comunicação é uma ferramenta utilizada para promover a saúde pública, e diante da pandemia da COVID-19, é imprescindível que a população tenha acesso ao debate qualificado e a informações seguras sobre a doença. Tomar a adoção de medidas preventivas, principalmente de conscientização da população nas práticas de higiene, medidas de distanciamento e isolamento social, são estratégias essenciais para evitar a disseminação da doença. O objetivo do projeto foi conscientizar a população, bem como os grupos de risco sobre a prevenção, cuidados e manutenção da saúde durante o período de pandemia do COVID-19, através de ciclos de debates, podcasts na rádio e postagens nas redes sociais. Como resultado do evento foram produzidos 39 podcasts e 13 bate papos ao vivo, sendo observado durante a realização das atividades uma grande participação popular, podendo concluir que informações seguras e atualizadas foram divulgadas em momentos importantes no cenário encontrado, contribuindo com a educação em saúde de uma parcela considerável da população.

Palavras-chave: Infecções por Coronavirus, Saúde Pública, Rádio, Comunicação.

\begin{abstract}
Coronavirus 2019 disease (COVID-19) is an infectious respiratory disease of viral cause, having its origin in China and soon spread throughout the world becoming a pandemic and public health emergency. Communication is a tool used to promote public health, and in view of the COVID-19 pandemic, it is essential that the population have access to qualified debate and safety information about the disease. Taking preventive measures, mainly to raise awareness of the population in hygiene practices, distance measures and social isolation, are essential to prevent the spread of the disease. The project's objective was to raise awareness among a population, as well as groups at risk about prevention, care and health maintenance during the COVID-19 pandemic period, through cycles of debates, radio podcasts and posts on social networks. As a result of the event, 39 podcasts and 13 live chats were obtained, with great popular participation being observed during the activities, and it can be concluded that safe and up-to-date information was disclosed at important moments in the scenario found, contributing to health education in an addition portion of the population.
\end{abstract}

Keywords: Coronavirus Infections, Public Health, Radio, Communication.

\section{INTRODUÇÃO}

O Coronavírus 2019 (COVID-19) trata-se de uma doença respiratória infecciosa causada pelo vírus SARS-CoV-2, tendo seu primeiro caso detectado em Wuhan na China, em dezembro de 2019. Após sua identificação, a doença se espalhou rapidamente, sobrecarregando clínicas e hospitais em todo o mundo, 
porém somente em março de 2020 declarado pela Organização Mundial da Saúde como pandêmico o até então surto grave de COVID-19 (PAN, 2020; ZHU, 2020).

Em 26 de fevereiro de 2020, foi diagnosticado o primeiro caso de infecção no Brasil, na cidade de São Paulo. Mais tarde, foi confirmado os primeiros casos da nova doença no estado do Paraná. Sendo no dia 20 de março anunciado pelo Ministério da Saúde (MS) o estado de transmissão comunitária em todo território nacional (CRODA, 2020; MS, 2020; SESA, 2020). De acordo com dados do informe epidemiológico da secretaria de saúde do Paraná, os casos de COVID-19 cresciam exponencialmente e não se limitavam somente à capital, bem como estavam presentes nas cidades do interior do estado, tornando assim medidas preventivas para disseminação da SARS-CoV-2 também necessárias nestas regiões (SESA, 2020; SINGH, 2020).

O momento atual demonstrava de maneira clara, como exercer o direito à comunicação e o direito à informação, é central para a garantia do direito à saúde. De acordo com o Instituto de Comunicação e Informação em Saúde a comunicação e a informação são elementos centrais no combate à pandemia. Sobretudo, a internet tem sido espaço fundamental para que as pessoas acessem informação de qualidade sobre a crise sanitária, por meio de sites, portais, aplicativos e outros recurso disponibilizados pelos poderes e instituições públicas (FIOCRUZ, 2020).

No caso do rádio, a divulgação científica do campo tem papel fundamental na transmissão do conhecimento, no incremento e visibilidade de pesquisas e no amadurecimento acadêmico dos investigadores. Pesquisadores estudaram o rádio como veículo disseminador da ciência e do conhecimento e destacam sua importância no cenário comunicacional, neste sentido específico (PRATA, et al; 2019). Com base nisso, a utilização de diversas vias de propagação de informações, sendo a comunicação uma valiosa ferramenta para promover saúde, o objetivo deste evento foi conscientizar a população de forma geral, bem como os grupos de risco sobre a prevenção, cuidados e manutenção da saúde durante o período de pandemia da COVID-19, através de ciclos de debates e podcasts na rádio e postagens nas redes sociais.

\section{MÉTODOS}

O evento de extensão foi realizado em parceria da Universidade Estadual do Norte do Paraná - UENP com o Instituto Federal do Paraná (IFPR) - Campus Jacarezinho, 19a Regional de Saúde, CISNORP, PASCOM diocesana de Jacarezinho e Rede Educadora de Comunicação, com início das atividades no mês de julho de 2020 e encerrou em outubro do ano de 2020, totalizando 3 meses de atividades. Os profissionais e professores colaboradores, assim como os integrantes do projeto produziram materiais com informações atualizadas e seguras sobre prevenção, cuidados e manutenção da saúde durante o período da pandemia do novo coronavírus. A partir disso, foram realizados ciclos de debates semanais na Rádio Educadora FM em prol da saúde da população do Norte Pioneiro, ouvintes da rádio e seguidores das 
redes sociais; sendo os conteúdos gravados e reproduzidos nas instalações Rede Educadora de Comunicação (FM 90,9), localizada no município de Jacarezinho-PR. A cada semana um tema era abordado, sendo este determinado de acordo com as necessidades de demanda de informação para aquele momento. Dentro do tema já estabelecido, eram gravadas três chamadas com aproximadamente 5 minutos, essas eram transmitidas três vezes na semana durante a programação da rádio. Aos sábados das $12 \mathrm{~h} 30$ às 13h00 foram realizados programas com especialistas na temática semanal, sendo este transmitido ao vivo na rádio e no Facebook "Educadora FM 90,9 de Jacarezinho-PR". Posteriormente tanto as chamadas semanais e o programa ao vivo de sábado foram disponibilizados em formato podcast no aplicativo para Android "Rede Educadora FM", Facebook e Youtube da rádio.

\section{RESULTADOS}

Durante o período de atividade do evento de extensão foram produzidos 39 podcasts de 5 minutos 13 bate papos ao vivo com as seguintes temáticas: biossegurança, gestantes e a COVID-19, saúde mental durante a pandemia, doenças crônicas e a COVID-19, doenças respiratórias e a COVID-19, saúde mental durante a pandemia, saúde do idoso e a COVID-19, saúde da criança e a COVID-19, atividade física durante a pandemia, dor crônica e a COVID-19, tabagismo e a COVID-19, tais temáticas foram desenvolvidas com a colaboração e/ou convite participação de psicólogos, psiquiatras, nutricionistas, obstetras, enfermeiros da rede municipal de saúde, parceria com mestrandos especializados da Universidade Estadual Paulista UNESP, além de professores da UENP de diversas áreas da saúde como Fisioterapia e Educação Física. Para o ciclo de debates, na última semana foram divulgadas atividades de extensão realizadas pelo Centro de Ciências da Saúde - CCS durante o período de pandemia, informando a comunidade externa projetos e ações nos quais poderiam participar.

Os alunos integrantes do projeto foram responsáveis por acompanhar os programas de sábado e auxiliar os professionais com a transmissão no facebook, organização das perguntas dos ouvintes, divulgação em redes sociais, mensagens no whatsapp e gravações semanais; durante a elaboração do evento houve uma grande interação com instituições externas à universidade, com estas auxiliando no processo de produção de conteúdo e divulgação dos programas, isto graças à parceria com a 19ª Regional de Saúde, CISNORP, PASCOM diocesana de Jacarezinho, com a Rede Educadora de Comunicação e com o Instituto Federal do Paraná (IFPR) - Campus Jacarezinho.

Observou-se grande número de participação popular de diversas localidades, realizando perguntas a respeito dos temas semanais através de ligação para o telefone rádio no momento ao vivo dos programas de sábado ou enviando em forma de mensagens por meio da transmissão no facebook. Pudemos perceber que a transmissão via rádio permanece sendo uma fonte de informação importante para a população, principalmente a de adultos mais velhos, estes que são considerados um dos principais grupos de risco para 
a COVID-19. Além disso, acreditamos que atividades de extensão são uma forma de ampliar a atuação da universidade, oportunizando alunos e profissionais a experiências diferentes encontradas dentro da sala de aula. Dessa forma, com a realização dessa ação tivemos um papel fundamental na divulgação de informações científicas e de qualidade para a comunidade externa da região, interagindo e transformando a realidade social.

\section{CONCLUSÃO}

Podemos concluir que os objetivos do evento foram alcançados, informações seguras e atualizadas foram divulgadas em momentos importantes no cenário encontrado. As visualizações e participações foram satisfatórias e continuam agregando educação em saúde a quem teve ou terá acesso ao material fornecido. 


\section{REFERÊNCIAS}

CRODA, J; OLIVEIRA, W. K; FRUTUOSO, R. L; MANDETTA, L. H; SILVA, Djane C. B; SOUSA, J. D. B; MONTEIRO, W .M; LACERDA, M. V. G (2020). COVID-19 in Brazil: advantages of a socialized unified health system and preparation to contain cases. Journal of the Brazilian Society of Tropical Medicine, 53 (20200167), 1-6.

BRASIL. Ministério da Saúde (2020). Portal do COVID-19. Painel de casos de doença pelo coronavírus 2019 (COVID-19) no Brasil. Retrieved from (covid.saude.gov.br/).

ICICT FIOCRUZ (2020). Emergência da COVID-19 sinaliza importância da informação e comunicação para a saúde. Retrieved from < https://www.icict.fiocruz.br/content/emerg\%C3\%AAncia-da-covid-19sinalizaem: import\%C3\%A2ncia-da-informa\%C3\%A7\%C3\%A3o-e comunica\%C3\% A7\%C3\%A3opara-sa\%C3\%BAde.>.

PAN, An et al (2020). Association of public health interventions with the epidemiology of the COVID-19 outbreak in Wuhan, China. Jama, 323(19):1915-1923.

PRATA, N; MARTINS, H. C; AVELAR, K. M (2020). A divulgação científica sobre rádio no Brasil: Um estudo da revista Rádio-Leituras. Estudos em Comunicação, Universidade Federal de Ouro Preto - FUMEC, v. 1 , n. 29, p. 159-175, dez./2019. Retrieved from <http://ojs.labcomifp.ubi.pt/index.php/ec/article/view/406>.

SESA - SECRETARIA DA SAÚDE DO PARANÁ GOVERNO DO ESTADO (2020). Coronavírus (covid-19). Retrieved from: 〈http://www.saude.pr.gov.br/Pagina/ Coronavirus-COVID-19>.

SINGH, D. R; SUNUWAR, D. R; KARKI, K; GHIMIRE, S; SHRESTHA, N (2020). Knowledge and Perception Towards Universal Safety Precautions During Early Phase of the COVID-19 Outbreak in Nepal. Journal of Community Health. 